Research Journal of Applied Sciences, Engineering and Technology 6(19): 3484-3488, 2013

DOI:10.19026/rjaset.6.3550

ISSN: 2040-7459; e-ISSN: 2040-7467

(C) 2013 Maxwell Scientific Publication Corp.

$\begin{array}{lll}\text { Submitted: August 10, } 2012 & \text { Accepted: September 17, } 2012 & \text { Published: October 20, } 2013\end{array}$

\title{
Research Article Investigating the Condition of components of Knowledge Management in Hexa Consulting Engineers Company (Iran/Tehran)
}

\author{
Maryam Soleimani, Mohammad Javad Bafrani, Mozhgan Hamidi Beinabaj and \\ Mohammad Ali Hasanabadi \\ Department of Management, Economics and Accounting, Payame Noor University, \\ P.O. Box 19395-3697 Tehran, Iran
}

\begin{abstract}
The current study aims at investigating the condition of components of knowledge management in Hexa Consulting Engineers Company (Iran/Tehran). The study was conducted using the descriptive-field method. Statistical population included managers and experts of Hexa Consulting Engineers Company and the sample consisted of forty seven of them. Questionnaire was tool of data collection. Data was collected in cross-sectional form in July-August 2011. The main questions posed were as follows: 1) How is the condition of components of knowledge management among managers and experts. 2) Is there a meaningful relationship between different components of knowledge management. 3) Are these components of equal value and importance. Data analysis was carried out using both descriptive and inferential methods (Including One-Sample T Test, The Friedman Test and Spearman Correlation Coefficient). Spss ver.15 software was utilized to complete the analysis. Level of transfer of knowledge was assessed as average. Creation of knowledge and storage and archiving of knowledge were evaluated at a level lower than the average level. There were meaningful relationships among all components of knowledge management and creation of knowledge was given the highest rank by the respondents. According to the obtained results effective use of organizational knowledge through modern tools such as knowledge management is a challenge faced by the company under study and this intensifies the need focusing on mechanisms that can enhance components of knowledge management.
\end{abstract}

Keywords: Creation of knowledge, knowledge management, storage and archiving of knowledge, transfer of knowledge

\section{INTRODUCTION}

Knowledge management has been considered as the main axis of several activities in organizations in the current knowledge economy. Importance of knowledge management lies in the fact that it could result in empowerment of individuals and the organization through organizing of knowledge in order to perform activities effectively (Jantz, 2001). Knowledge management facilitates ongoing learning processes, decreases forgetfulness and minimizes the necessity for creating of major changes from top to bottom in the organization (Malhotra, 1999). So, services of organizations will be improved by implementing of knowledge management (Jantz, 2001). Given the importance of knowledge management in organizations, main purpose of this research is to investigate the condition of components of knowledge management in Hexa Consulting Engineers Company (Iran/Tehran). Therefore, first literature related to knowledge management will be studied. Then research methodology and findings are illustrated. Finally, discussion and conclusion and recommendations will be represented.

\section{LITERATURE REVIEW}

Today clear-sighted believe that knowledge has been changed to transition axis of global economy and origin of value-creation in organizations (Kakabadse and Kakabdse, 2003), as Francis Bacon has emphasized on importance of knowledge management in organizations with his famous phrase "knowledge is power" (Muller-Merbach, 2005). This issue demonstrates the necessity for programming, organizing, leadership and stability of knowledge management as well as process of having access to proper knowledge in an efficient and impressive manner (Kelly, 2004).

The strategy that considers knowledge along with other resources such as land, work and capital as an asset is knowledge management (Nonaka and Takuchi, 1995). There is no agreement about definition of knowledge management among the clear-sighted.

Corresponding Author: Maryam Soleimani, Department of Management, Economics and Accounting, Payame Noor University, P.O. Box 19395-3697 Tehran, Iran

This work is licensed under a Creative Commons Attribution 4.0 International License (URL: http://creativecommons.org/licenses/by/4.0/). 
O'Dell (1996) believes that knowledge management is a systematic approach for finding, understanding and applying of knowledge in order to create knowledge. According to Seemann et al. (1999) knowledge management is intelligent planning of processes, tools, structures and etc with the purpose of increasing, restructuring, sharing or improving of knowledge application that is apparent in each of three elements of mental capital, i.e., structural, human and social. Some of the clear-sighted believe that knowledge management is not a technology (Clair, 2002; Lang, 2001; DiMatta and Norman, 1997; Koenig and Srikantai, 2002; McInerey, 2002). In spite of different viewpoints about definition of knowledge management, function of this process in organizations especially learner organizations is the important issue.

This process helps organizations to be able to use their assets, work faster and more wisely and obtain more capital (Schwarzwalder, 1999). If knowledge management is executed in organizations, knowledge of each individual will be changed in to organizational knowledge and individuals will be able to share their knowledge extensively. Knowledge management provides the opportunity for employees to produce outputs which have roots in their abilities, thoughts and ideas (Esfandiary and Zakerifard, 2007).

While stability and evaluation of components of a concept is necessary in order to implement each concept in the organization, therefore, it is essential to examine and evaluate knowledge management components in organizations before implementation of it. Various models have been represented by clearsighted for evaluating of knowledge management. These models include two to eight processes and most of them are similar to each other in terms of content. Creation, transfer and storage of knowledge are cited as major processes of knowledge management in many of these models. For instance, these processes form major parts of Despers and Chauvel (1999), Wiig (1997), Alavi and Leidner (2004), Jashapara (2004) and Rao (2005) model.

Creating or developing of knowledge contains collection of swift and creative, systematic and programmed activities that are in the direction of extending of scientific knowledge borders and human beings' knowledge treasury (Saeeidi and Ali, 2006). Knowledge transfer means sharing of the current knowledge, accessibility and the manner of its transfer from individual level to group level and finally organizational knowledge. Storage of knowledge is keeping and up-to-dating of knowledge, so as to prevent from its destruction and provides the possibility of its application (Afraze, 2006).

Given the important role that knowledge management could play in improving of organizations' performance, the researcher wants to evaluate such process in Hexa Consulting Engineers Company. Evaluation of knowledge management is done with studying of the most important components of it (creating, storage and transferring of knowledge). In the following, data analysis is represented; afterwards research findings and conclusions are illustrated.

\section{DATA ANALYSIS}

Research methodology, research questions and applied statistical methods are described in this section.

Research methodology: This research is conducted using descriptive-field method. Statistical population of the research is consisted of managers and experts of the Hexa Consulting Engineers Company. We had taken a sample of 47 from managers and experts who were selected randomly. Researcher self-made questionnaire is the tool of data collection including two parts of demographic information and knowledge management. Age, gender, working experience and Organizational job were studied in the part related to demographic information. Knowledge management was studied with fifteen questions. Likert five-point scale was utilized to score the questionnaire's options (from $1=$ very low to $5=$ very high). Data was collected in cross-sectional form in July-August 2011. Content validity of the questionnaire was confirmed by professors and experts in management field and cronbach alpha method was used to determine reliability. Cronbach alpha was calculated equal to $95 \%$ for questions of knowledge management which showed strong reliability of the questionnaire.

\section{Research questions: \\ Research questions are:}

- How is the condition of components of knowledge management among managers and experts?

- Is there a meaningful relationship between different components of knowledge management?

- These components of equal value and importance?

\section{STATISTICAL METHODS}

Data analysis was carried out using both descriptive and inferential statistics (one sample t-test, Spearman Correlation, Friedman Test) and Spss ver.15 software. Spearman correlation test was used because of qualitativeness of the studying variables.

Findings: Descriptive results related to demographic variables are represented in Table 1 and 2.

According to descriptive results $53.2 \%$ of respondents were in age-group 20-35 year old. Among 
Res. J. Appl. Sci. Eng. Technol., 6(19): 3484-3488, 2013

Table 1: Results of descriptive analysis related to demographic variables

\begin{tabular}{llllll}
\hline Age & Frequency & Percentage & Work experience & Frequency & Percentage \\
\hline $20-35$ & 25 & 53.2 & $<5$ & 5 & 17 \\
\\
$36-50$ & & & $5-10$ & 7 & 36.2 \\
& 16 & 34 & $11-15$ & 5 & 14.9 \\
$>50$ & & 12 & $>20$ & 13 & 10.6 \\
\hline
\end{tabular}

Table 2: Zresults of descriptive analysis related to demographic variables

\begin{tabular}{llllll}
\hline Frequency & Percentage & Organizational job & Frequency & Percentage & Gender \\
\hline 40.4 & 19 & Manager or supervisor & 83 & 36 & Man \\
59.6 & 28 & Expert & 17 & 8 & Woman \\
\hline
\end{tabular}

Table 3: Results of one-sample t-test for components of knowledge management

\begin{tabular}{llllllll}
\hline & \multicolumn{1}{c}{} & \multicolumn{1}{c}{} & & & \multicolumn{2}{c}{ Fiducial interval of 95\% for mean difference } \\
Variable & Mean & S.D & Average amount & Sig. & T & df & Low limit \\
\hline Knowledge creation & 16.65 & 4.2 & 18 & 0.037 & -2.15 & 46 & -2.59 \\
Knowledge transfer & 15.3 & 3.7 & 15 & 0.53 & 0.619 & 46 & -0.76 \\
Storage of knowledge & 10.9 & 3 & 12 & 0.019 & -2.42 & 46 & -1.94 \\
Knowledge management & 42.9 & 9.12 & 45 & 0.128 & -1.55 & 46 & -4.74 \\
\hline
\end{tabular}

them $36.2 \%$ (the highest number) had work experience of 5 to 10 years; $83 \%$ of respondents were male and $40.4 \%$ had manager or supervisor positions.

We have used one-sample t-test in order to answer to the first question, i.e., the manner of condition of components of knowledge management. Mean of knowledge management components in this test was compared with the average amount. This test was performed for each component. Significance level of knowledge transfer is more than 0.05 among knowledge management components that illustrates this component doesn't have a significant difference with average amount. In other words knowledge transfer in the intended company is at an average level. Results demonstrate significance of two components of knowledge creation and storage of knowledge is less than 0.05 which shows level of these components has a significant difference with average amount. As amounts related to two columns of higher and lower limits of confidence interval are negative for components of knowledge creation and storage and archiving of knowledge status of these components is evaluated at a level lower than the average level. Results show that knowledge management status (sum of three components) is generally at an average level (Table 3 ).

This result is in accordance with results of other researches including (Shirvani et al., 2010) in Isfahan Medical Sciences Faculty. They consider processes of knowledge management as identification, acquisition, sharing and distribution, utilization, storage and archiving of knowledge and estimate all these processes at a lower amount of mean level. In Mirghafuri et al. (2010) components of strategy and purpose, gaining and creating, maintaining and documentation, sharing, implementation and evaluation were considered for studying of knowledge management in healthcare section in Yazd province. According to results of this research, the only condition related to knowledge implementation was higher than average amount and other components and also the total process of knowledge management were estimated lower than average. Semarasl (2007) has confirmed existence of distance between the existing knowledge and favorable knowledge in research and petrochemical technology organization. In Tabibi et al. (2009) in educational and treatment centers in Zanjan province, knowledge management has been studied with components of creation, propagation and maintenance and storage knowledge. Condition of knowledge management was evaluated weak in this research.

Correlation among knowledge management components was studied in order to answer to the second question, i.e. existence or non-existence of a relation among knowledge management components. Results reveal that there is a strong significant relation between knowledge creation and knowledge transfer with correlation coefficient of 0.438 and between knowledge creation and storage and archiving of knowledge with correlation coefficient of 0.458 . Knowledge transfer and storage and archiving of knowledge have a significant relation with correlation coefficient of 0.403 . The highest amount of correlation coefficient $(0.458)$ belongs to the relation between knowledge creation and storage and archiving of knowledge (Table 4). This result demonstrates that by increasing (or decreasing) of each of the components of creation, transfer and storage and archiving of knowledge, other components will increase (or decrease). Existence of relation among components of knowledge management has been confirmed in other researches too. Among such researches we can refer to Khadem Abbass (2009). Existence of strong and 
Res. J. Appl. Sci. Eng. Technol., 6(19): 3484-3488, 2013

Table 4: Results of correlation coefficient between knowledge management components

\begin{tabular}{llll}
\hline Knowledge management components & Knowledge creation & Knowledge transfer & Storage of knowledge \\
\hline Knowledge creation & 1 & $0.438^{* *}$ & $0.458^{* *}$ \\
Knowledge transfer & $0.438^{* *}$ & 1 & $0.403^{* *}$ \\
Storage of knowledge & $0.458^{* *}$ & $0.403^{* *}$ & 1 \\
\hline
\end{tabular}

$\mathrm{p}<0.01^{* *} \mathrm{p}<0.05^{*}$

Table 5: Significance of friedman test

\begin{tabular}{ll}
\hline Index & Amount \\
\hline Number & 47 \\
$\mathrm{X}^{2}$ & 60.218 \\
Degree of freedom & 2 \\
Significance & 0.000 \\
\hline
\end{tabular}

Table 6: Results of Friedman test for knowledge management components

\begin{tabular}{ll}
\hline Knowledge management components & Average amount of rank \\
\hline Knowledge creation & 2.59 \\
Knowledge transfer & 2.29 \\
Storage of knowledge & 1.13 \\
\hline
\end{tabular}

significant correlation among components of knowledge acquisition, propagation and responsiveness has been proven in this research. Darroch (2005) has confirmed existence of a relation between knowledge acquisition, propagation and responsiveness towards knowledge with $99 \%$ confidence in his research. Attafar and Soleimani (2011) concluded the significant relationship between knowledge creation, knowledge transfer and storage and archiving of knowledge too.

Friedman test was used in order to study assimilation of importance of knowledge management components in viewpoint of managers and experts of Hexa Consulting Engineers Company (third question). With due attention to represented results in Table 5, hypothesis zero is rejected on $95 \%$ level since amount of significance level is zero and is far lower than researcher's alpha $(\alpha=95 \%)$. In other words, importance of knowledge management components is not identical in managers and experts' viewpoint. Average amount of these factors' rank is shown in Table 6. Given the significance of relations, we can claim that knowledge creation factor (with mean rank of 2.59) has the highest importance.

\section{CONCLUSION}

According to results of this research, level of transfer of knowledge was assessed as average. Creation of knowledge and storage and archiving of knowledge were evaluated at a level lower than the average level. In addition knowledge management status (sum of three components) was generally at an average level. In other words, creating, transferring and storage and archiving of knowledge don't have a favorable condition in this company. By paying attention to results of this research and other performed researches in other organizations of the country we can say knowledge management hasn't been institutionalized in many organizations yet. This reality along with much importance of knowledge management for organizations puts emphasis on the necessity of paying attention to this process by managers.

Other results reveal that there is a significant relation among components of knowledge management. Therefore we can claim that appropriate enjoyment of the organization from each of the knowledge management components is spontaneously resulted in reinforcing of other components; similarly lack of them or their weakness will have negative effect on other components.

Another result demonstrates that importance of knowledge management components is not identical in managers and experts' viewpoint. Component of knowledge creation have the highest importance in viewpoint of managers and experts in the company under study.

Generally, results of the current research illustrate that knowledge management doesn't have a favorable condition in the studying company. Given the importance of knowledge management in creating of competitive power for organizations, it is necessary for managers to think about strategies in order to reinforce this process. It is obvious that existing of relation among knowledge management components is resulted in reinforcing of each component which causes reinforcement of other components. So, the following applied recommendations are represented to reinforce knowledge management components:

Establishing of mechanisms for reinforcement of knowledge creation through holding of public sessions with the presence of employees in order to discuss about important problems and issues of the organization; regular evaluation of employees' performance and appointment of individuals in organizational jobs with due attention to their skills and proficiencies.

Availability of the more recent information for employees, transferring of knowledge to employees while working, transferring of positive experiences of employees to each other and directing of newly-arrived individuals through experienced employees for reinforcement of knowledge transfer

Reinforcement of keeping and storage of knowledge through collecting, selecting, classifying, organizing and documenting of organizational 
information, knowledge and experiences; and applying of appropriate tools and methods for regulation and filtration of information and creating of data bases.

\section{REFERENCES}

Alavi, M. and D.E. Leidner, 2004. Knowledge management and knowledge management systems: Conceptual foundations and research issues. MIS Quart., 25(1): 36-107.

Afraze, A., 2006. Knowledge Management (Concepts, Models, Measurement and Implementation), Amir Kabir University Press, Tehran.

Attafar, A. and M. Soleimani, 2011. Investigating the condition of components of knowledg management in libraries of isfahan. Indiscip. J. Contemp. Res. Bus., 2(12).

Clair, G.S., 2002. Knowledge Services: Your company's key to performance excellence. Inform. Outlook, 6(6): 26-33.

Darroch, J., 2005. Knowledge Management: Innovation and Firm performance. J. Knowl. Manag., 9(3): 11-105.

Despers, C. and D. Chauvel, 1997. Knowledge management. J. Knowl. Manag., 3(2): 110-120.

DiMatta, S. and O. Norman, 1997. Knowledge Management: Hope or harbinger? Lib. J., 15: 53-55.

Esfandiary, M.A. and F. Zakerifard, 2007. Using of intranet as a tool for knowledge management in university libraries. J. Librarian. Inform., 2: 199-217.

Jantz, R., 2001. Knowledge management in academic libraries: Special tools and processes to support information professionals. Ref. Serv. Rev., 29(1): 33-39.

Jashapara, A., 2004. Knowledge Management: An Integrated Approach. Pearson Education Ltd., Prentice Hall, Essex.

Kakabadse, N.K. and K. Kakabdse, 2003. Reviewing the knowledge management literature: towards a taxonomy. J. Knowl. Manag., 7(4): 75-91.

Kelly, C., 2004. Knowledge Management: Just doing it. Manag. Inform., 11(6): 43-47.

Khadem Abbass, S., 2009. Relation between procedures of knowledge management and level of innovation in organizations, case study: Sub-category corporations of selected economic firms in Isfahan. MA Thesis, Administrative Sciences and Economy Faculty of Isfahan University.

Koenig, M.E.D. and A.H.T. Srikantai, 2002. The business world discovers the assets of librarianship. Inform. Outlook, 6(4): 14-18.

Lang, J.C., 2001. Managerial concerns in knowledge management. J. Knowl. Manag., 5(1): 43-57.
Malhotra, Y., 1999. Knowledge management, knowledge organizations and knowledge workers: A view from the front lines, Retrieved from: www.brint.com/interview/maeil.htm.

McInerey, C., 2002. Knowledge management and the dynamic nature of knowledge. J. Am. Soc. Inform. Sci. Technol., 53(12): 1009-10018.

Mighafuri, Seyed Habib Alah; Farhangnejad, Mohammad Ali; Sadeghi Arani, Zahra. 2010. Evaluation of performance of healthcare section in Yazd province in utilizing of knowledge management process. J. Health Manag., 13(39): 79-88.

Muller-Merbach, H., 2005. Francis Bacons praise: Knowledge, the source of power. Knowl. Manag. Res. Pract., 3(4): 45-46.

Nonaka, I. and R. Takuchi, 1995. Knowledge Creating Organizations. Oxford University Press, New York.

O’Dell, C., 1996. A current review of knowledge management best practice. Conference on Knowledge Management and the Transfer of Best Practices, Business Intelligence, London.

Rao, M., 2005. The Social Life of KM Tools. Knowledge Management Tools and Techniques: Practitioners and Experts Evaluate KM Solutions. Elsevierp, Oxford, pp: 1-73.

Saeeidi, K. and A. Ali, 2006. Research and development: Producer of creativity and innovation. Res. J. Meth., 15(98): 5-21.

Schwarzwalder, R., 1999. Librarians as knowledge management agents. Econtent, 22(2): 63-65.

Seemann, P., D. De Long, S. Stucky and E. Guthrie, 1999. A strategic framework for investing in intellectual capital PAKeM99 proceedings. The Practical Application Company Ltd., pp: 229.

Semarasl, N., 2007. Quantifying the distance between existing and desired knowledge in the organization of petrochemical research and technology and strategies for omitting the distance. M.Sc. Thesis, Allameh Tabatabaee University, Tehran, (In Persian).

Shirvani, A., A. Safdarian and A. Alavi, 2010. Sovereignty level of knowledge management in Isfahan medical sciences university. J. Health Inform. Manag., 6(1): 75-82.

Tabibi, S.J.A., N. Pour, A. Ashkan and Z.V. Sahar, 2009. Relation of organizational culture and knowledge management in treatment educational centers in Zanjan province. Scientific-Res. J. Med. Sci. Univ. Zanjan, 17(69): 84-91.

Wiig, K.M., 1997. Integrating intellectual capital and knowledge management. J. Long Range Plann., 30(3): 399-405. 